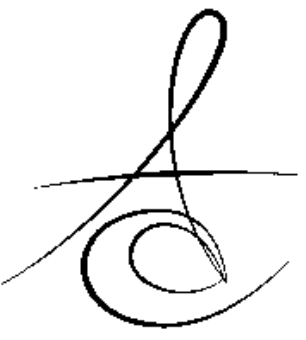

\section{İKİ FARKLI DİŞ MACUNUNUN FARKLI RESTORATİF MATERYALLERİN YÜZEY PÜRÜZLÜLÜĞÜ ÜZERİNE ETKİSİ}

\section{EFFECT OF THE TWO DİFFERENT TOOTHPASTES ON SURFACE ROUGHNESS OF DIFFERENT RESTORATIVE MATERIALS}

\author{
Yrd. Doç. Dr. Kanşad PALA*
}

Arş. Gör. Hale KARAKUYU**

\author{
Yrd. Doç. Dr. Neslihan TEKÇE ${ }^{* *}$ \\ Doç. Dr. Emre ÖZEL ${ }^{* *}$
}

Makale Kodu/Article code: 2443

Makale Gönderilme tarihi: 22.10 .2015

Kabul Tarihi: 01.07.2016

\section{ÖZET}

Amaç: Bu çalışmanın amacı, diş macunlarının farklı restoratif materyallerin yüzey pürüzlülüğüne etkisini incelemektir.

Gereç ve Yöntem:Bu çalışmada toplam 40 adet kompozit disk oluşturulmuştur. Kompozit diskler iki direkt kompozit [Aelite All Purpose Body (Bisco, Schaumburg, IL, Amerika), Clearfil Majesty Posterior, (Kuraray Medical Inc, Tokyo, Japonya)], bir indirekt [Epricord (Kuraray)] kompozit ve bir kompomer [(Dyract XP (Dyract $X P$, Dentsply, Konstanz, Almanya)] materyallerinden oluşturulmuştur $(n=10)$. Hazırlanan kompozitlerin cilaları PoGo kitleri ile yapılmıştır. Her bir grupta yer alan kompozitler ikiye ayrılmış $(n=5)$ ve bu alt gruplara iki farklı diş macunu (Colgate, Sensodyne) bir elektrikli diş fırçası aracılığıyla 12 dakika boyunca uygulanmıştır. Her bir örneğin başlangıç, cila sonrası ve diş fırçalama sonrası değerleri ayrı ayrı kaydedilmiştir. İstatistiksel analizler repeated tek yönlü varyans analizi (Anova) ile yapılmıştır $(p<0.05)$.

Bulgular:Bütün gruplarda en düşük pürüzlülük değerlerini anlamlı olarak şeffaf bant altında hazırlanan örnekler sergilemiştir $(p<0.05)$. Polisajdan sonra en düşük pürüzlülük değerini Aelite $(0,347 \pm 0,21)$, en yüksek pürüzlülük değerlerini Dyract XP $(0,453 \pm 0,11)$ sergilemiştir ( $p>0.05)$.

Sonuç: Bu çalışmada kullanılan bütün restoratif materyaller iki farklı diş macunu ile fırçalanma işlemi arkasından istatistiksel olarak başlangıç değerleri ile benzer sonuçlar sergilemiştir. Ancak Sensodyne; Aelite, Majesty Posterior ve Dyract XP'nin pürüzsüzlüğünü hafif düzeyde geliştirirken, Colgate Epricord ve Dyract XP'nin pürüzsüzlüğünü hafif düzeyde geliştirmiştir.

Anahtar Kelimeler: Rezin kompozit, mikrohibrit, nanohibrit, diş macunu, yüzey pürüzlülüğü

\section{ABSTRACT}

Aim: The aim of this study was to investigate the effect of toothpastes on surface roughness of different restorative materials.

Materials and Methods: 40 composite discs were created for this study. Composite disc are constituted from two direct composites [Aelite All Purpose Body (Bisco, Schaumburg, IL, USA), Clearfil Majesty Posterior, (Kuraray Medical Inc, Tokyo, Japan)], an indirect composite [Epricord (Kuraray)] and a compomer [(Dyract XP (Dyract XP, Dentsply, Germany)] $(n=10)$. The PoGo kit was used for finishing and polishing procedures. Each composite group were divided into two $(n=5)$ and two different toothpaste (Colgate, Sensodyne) were applied by an electric toothbrush for 12 minutes. Initial values, and after polishing and tooth brushing values for each material were recorded separately. Statistical analysis was performed by one-way ANOVA $(p<0.05)$.

Results: In all groups; the lowest roughness values were obtained from examples prepared under the mylar strip (significantly) $(\mathrm{p}<0.05)$. After polishing, Aelite $(0.347 \pm 0.21)$ exhibited the lowest roughness values, and Dyract XP $(0.453 \pm 0.11)$ exhibited the highest values ( $p>0.05)$.

Conclusion: All restorative materials used in this study exhibited statistically similar results after tooth brushing with two different toothpastes according to baseline. Sensodyne improved smoothness of Aelite, Majesty Posterior and Dyract XP, while Colgate improved smoothness of Epricord and Dyract XP.

Keywords: Resin composite, microhybrid, nanohybrid, toothpaste, surface roughness.

\footnotetext{
${ }^{*}$ Erciyes Üniversitesi Diş Hekimliği Fakültesi, Restoratif Diş Tedavisi AD

${ }^{* *}$ Kocaeli Üniversitesi Diş Hekimliği Fakültesi, Restoratif Diş Tedavisi AD
} 


\section{GİRIŞ}

Kompozit sistemler ortaya çıkışlarından bu yana büyük değişim ve gelişmeler göstermiş, adeziv sistemlerdeki ilerlemeler ile birlikte günlük diş hekimliği uygulamalarının vazgeçilmez bir parçası olmuştur. ${ }^{1}$ Kompozitlerin kliniklerde yaygın kullanım alanı bulmasında; hastaların estetik beklentilerinin artması, hekimlerin bu materyaller ile minimal invaziv tedavi şansı elde etmesi ve diş yapısına daha az zarar verilme ilkesinin sağlanmış olması etkilidir. ${ }^{2}$ Kompozit materyalinin içeriğinde yakın zamanda yapılan en önemli değişiklik; boyutu küçültülmüş güçlü doldurucu partiküllerin materyal kompozisyonuna eklenmiş olmasıdır. Materyal içeriğindeki inorganik partiküllerin gelişimi ile birlikte daha yüksek aşınma direncine sahip restorasyonlar elde edilirken, materyallerin cilalanabilirliği de gelişmiştir. Özellikle aşınma direncinin yükselmesi, sadece posterior restorasyonlar için değil, tüm ağız içi restorasyonların yapımında kullanılan kompozit materyal için gerekli olan bir iyileşme olmuştur. ${ }^{1,3,4}$

Kompozitler organik rezin içerisine dağılmış sert inorganik parçacıklardan oluşmaktadır. Kompozitlerin özellikleri; büyük ölçüde doldurucularının özelliklerinden, ayrıca monomerlerin yapısından etkilenmektedir. ${ }^{5,6}$ Restoratif materyallerin pürüzsüz yüzey sergilemeleri hem diş hem de çevre dokuların sağlıkı kalabilmeleri ve uygun estetik görünümün sağlanması açısından önemlidir. Pürüzlü bir restorasyon yüzeyi renkleşmeye, aşınma oranın artmasına, plak birikimine, restorasyonun parlaklığının azalmasına ve diş eti iritasyonlarına sebep olabilir. ${ }^{7-9}$ 0.7-1.4 $\mu \mathrm{m} \quad \mathrm{Ra}$ değerleri arasında elde edilen yüzey pürüzlülük değerlerinin plak birikimi açısından risk oluşturmadığı bildirilirken, ${ }^{10}$ bazı çalışmalarda ise $1 \mu \mathrm{m}$ 'den küçük Ra değerlerine sahip restoratif materyallerin, göz ile görünür şekilde düzgün bir yüzey sergiledikleri ifade edilmiştir. $^{11}$

Diş hekimliği alanında estetik beklentilerin artması, yalnızca direk kompozit restorasyonlara değil aynı zamanda indirek restorasyonlara da ilgiyi arttırmıştır. Günümüzde indirekt olarak kullanılan restoratif materyallerin estetik ve mekanik özellikleri önceki jenerasyonlara göre gelişmiştir. Ayrıca bu restoratif materyaller, klinik olarak ulaşılması zor olan bölgelerde indirekt olarak ulaşımın sağlanması ve fazla madde kayıplı dişlerde endikasyon alanı bulmaları sebebiyle direkt olarak kullanılan restoratif materyallere üstünlük sağlamaktadırlar. ${ }^{12,13}$ İndirek kompozit materyallerin bileşimleri geleneksel kompozit materyaller ile benzer olmasına rağmen, polimerizasyon yöntemlerinin farklı olması ile birbirlerinden farklılaşırlar. İndirekt kompozitlerin diğer materyallerden farklı olarak uzun süre ıSı ve ışık fırınında polimerize edilmesi bu materyallerin mekanik özelliklerinin diğerlerine göre üstün hale gelmesine sebep olmuştur. ${ }^{14,15}$

Günümüzde diş macunları ağız hijyeni sağlamak amacıyla yaşamımızın vazgeçilmez bir ürünü olmuştur. ${ }^{16}$ Diş macunu kullanılmasında ki amaç diş yüzeyini temizlemek ve polisajlamaktır. Diş macunlarını oluşturan maddeler; abrazivler (silikon oksit, alüminyum oksit, polivinil klorid), su, nemlendirici, deterjanlar, tat verici ajanlar, terapötik ajanlar (florid, pirofosfat), renk verici ajanlar ve koruyucu maddelerdir. ${ }^{17}$ Macunların içeriğinde \% 20-40 oranında çözünmeyen inorganik tuz olan abrazivler bulunur ve bu abraziv içerik diş macunlarına yüksek aşındırma özelliği kazandırır. ${ }^{17}$

Fırçalama işlemi, fırçanın mekanik etkisi ve diş macunun aşındırıcı içeriklerinin etkisiyle materyallerin yüzey özelliklerini etkiler. ${ }^{18-22}$ Kompozitlerin bileşimleri de yüzey pürüzlülük sonuçlarını etkileyen başka bir faktördür. Materyallerin yüzey pürüzlülüğündeki artış, yüzeyden madde kalkmasıyla birlikte materyallerde renk değişimine ve fiziksel özelliklerin bozulmasına sebep olarak restorasyonların klinik performansını etkileyebilir. Bu nedenle bu çalışmada; dört farklı estetik restoratif materyalin yüzey pürüzlülüğü üzerinde diş macunlarının etkisini incelemek amaçlanmıştır. Bir kör hipotez oluşturulmuştur; (1) farklı diş macunları, farklı restoratif materyaller üzerinde farklı yüzey pürüzlülük sonuçları sergilemezler.

\section{YÖNTEM VE GEREÇLER}

Bu çalışmada iki farklı diş macununun kompozitlerin yüzey pürüzlülüğü üzerindeki etkisi incelenmiştir. Farklı diş macunlarının kompozitlerin yüzey pürüzlülüğü üzerindeki etkisini incelemek amacıyla iki direkt [Aelite All Purpose Body (Bisco, Schaumburg, IL, Amerika), Clearfil Majesty Posterior, (Kuraray Medical Inc, Tokyo, Japonya)], bir indirekt [Epricord (Kuraray)] kompozit ve bir kompomer [(Dyract XP (Dyract XP, Dentsply, Konstanz, Almanya)] kullanılmıştır (Tablo 1). Paslanmaz çelikten bir teflon kalıp kullanılarak $8 \mathrm{~mm}$ 
çapında $2 \mathrm{~mm}$ kalınlığında örnekler hazırlanmıştır. Bir cam ve şeffaf bir polyester strip üzerine yerleştirilmiş kalıp içerisine konulan kompozit rezin fazlalıkları alınıp düzeltmeleri yapıldıktan sonra üzerine başka bir polyester strip yerleştirilerek bir ışık cihazı yardımıyla (3M Elipar S10, 3M ESPE St.Paul, MN, Amerika) üreticisinin önerdiği süreler doğrultusunda polimerize edilmiştir. Epricord'un polimerizasyonunda aynı üretici firmaya ait olan indirekt kompozit pişirme fırını (CS110 Light and Heat Curing System; Kuraray Medical Inc.,Tokyo, Japonya) kullanılmıştır. Epricord materyali ile hazırlanan bütün örnekler üretici firma önerileri doğrultusunda indirekt kompozit fırınında hazırlanmıştır. Tüm örnekler sertleştirildikten sonra kenar düzgünlükleri ve yüzey cilalama işlemleri Enhance\&PoGo cila kitleri (Dentsply, Konstanz, Almanya) kullanılarak tamamlanmıştır. Daha sonra tüm örnekler $37^{\circ} \mathrm{C}^{\prime}$ de 24 saat distile su içerisinde bekletilmiştir.

Tablo 1. Çalışmada kullanılan materyaller, üretici firma, içerik ve doldurucu oranları.

\begin{tabular}{|c|c|c|c|}
\hline Kompozitler & Sınıflama & İçerik & $\begin{array}{l}\text { Doldurucu } \\
\text { oranı } \\
\text { (Ağr/hac) }\end{array}$ \\
\hline \begin{tabular}{|c|} 
Aelite All \\
Purpose Body \\
(Bisco, \\
Schaumburg, \\
IL, Amerika)
\end{tabular} & Mikrohibrit & $\begin{array}{c}\text { Bis-EMA, TEGDMA, } \\
0.04-3.5 \mu \mathrm{m} \text { cam } \\
\text { doldurucu, amorf } \\
\text { silika. }\end{array}$ & $89 / 75$ \\
\hline $\begin{array}{l}\text { Clearfil Majesty } \\
\text { Posterior, } \\
\text { (Kuraray } \\
\text { Medical } \\
\text { Inc,Tokyo, } \\
\text { Japonya) }\end{array}$ & Nanohybrid & $\begin{array}{c}\text { Bis-GMA, TEGDMA, } \\
\text { hydrophobic aromatic } \\
\text { dimethacrylate, } 20 \\
\text { nm- } 1.5 \mu \mathrm{m} \text { cam } \\
\text { seramik, alümina } \\
\text { mikrodoldurucu, } \\
\text { silika. }\end{array}$ & $92 / 82$ \\
\hline $\begin{array}{c}\text { Epricord } \\
\text { (Kuraray } \\
\text { Medical Inc, } \\
\text { Tokyo, } \\
\text { Japonya) }\end{array}$ & Mikrohibrit & $\begin{array}{l}\text { UTMA, TEGDMA, } d \text { - } \\
\text { camphorquinone, } \\
\text { organik doldurucu, } \\
0.6 \mu \mathrm{m} \text { baryum } \\
\text { barosilikat cam, silika, } \\
\text { silanlanmış kolloidal } \\
\text { silika. }\end{array}$ & $85.5 /-$ \\
\hline \begin{tabular}{|c|} 
Dyract XP \\
(Dentsply \\
Caulk, Milford, \\
DE, Amerika)
\end{tabular} & \begin{tabular}{|c} 
Polyacid- \\
modified \\
kompozit \\
(kompomer)
\end{tabular} & $\begin{array}{c}\text { UDMA, TCB, TEGDMA, } \\
\text { TMPTMA, } d \text { - } \\
\text { camphorquinone, } \\
\text { ehyl-4 } \\
\text { (dimethylamino) } \\
\text { benzoate, butylated } \\
\text { hydroxytoluene, } \\
\text { stronsiyum-alumino- } \\
\text { sodyum-fluoro-fosfor- } \\
\text { silikat cam, } \\
\text { stronsiyum fluorid, } \\
\text { stronsiyum flourid } \\
\text { cam parçacıkları } \\
(0.8 \mu \mathrm{m}) \text {. }\end{array}$ & $47 / 50$ \\
\hline
\end{tabular}

Her bir materyalden 10 adet numune hazırlanmış, böylelikle toplam 40 adet disk oluşturulmuştur. Her gruba ait olan 10 diskten 5 tanesi Colgate Total (Colgate-Palmolive Company, New York, Amerika), 5 tanesi Sensodyne Çok Yönlü Koruma (Glaxo Smith Kline, Brentford, Middlesex, İngiltere) diş macunu ile fırçalanmıştır. Fırçalama işlemi bir elektrikli diş fırçası (Oral-B, Proffesional Care 3000, Procter \&Gamble, Weybridge, Surrey, İngiltere) aracılığı ile orta şiddetli (250 gram) sabit basınçta, ${ }^{22}$ toplam 12 dakika süresince yapılmıştır. ${ }^{23}$ Her bir diş macunu $40 \mathrm{ml}$ su ve $25 \mathrm{~g}$ diş macunun karıştırılması sonucu uygulanmıştır. Çalışmada kullanılan diş macunlarının içerikleri Tablo 2'de gösterilmiştir.

Tablo 2. Çalışmada kullanılan diş macunları ve içerikleri.

\begin{tabular}{|l|l|}
\hline $\begin{array}{l}\text { Çalışmada kullanılan } \\
\text { diş macunları }\end{array}$ & Diş macunlarının içeriği \\
\hline $\begin{array}{l}\text { Colgate Total } \\
\text { Colgate- } \\
\text { PalmoliveCompany, } \\
\text { New York, Amerika) }\end{array}$ & $\begin{array}{l}\text { Calcium carbonate, aqua, glycerin, } \\
\text { sodium lauryl sulfate, arginine, } \\
\text { cellulose gum, sodium bicarbonate, } \\
\text { tetra-sodium pyrophosphate, } \\
\text { benzyl-alcohol, sodium saccharin, } \\
\text { sodium hydroxide, sodium-mono- } \\
\text { fluorophosphates, arginine. }\end{array}$ \\
\hline $\begin{array}{l}\text { Sensodyne Çok } \\
\text { Yönlü Koruma } \\
\text { (GlaxoSmithKline, } \\
\text { Brentford, } \\
\text { Middlesex, İngilter) }\end{array}$ & $\begin{array}{l}\text { Sorbitol, hydrated silica, potassium } \\
\text { nitrate, cocamido propylbetaine, } \\
\text { aroma, aqua, xanthan gum, } \\
\text { titanium dioxide, sodium fluoride, } \\
\text { sodium saccharin, sodium } \\
\text { hydroxide, sucralose. }\end{array}$ \\
\hline
\end{tabular}

İlk ölçümler bütün materyallerin polimerize edilmesinin arkasından yapılmıştır. İkinci ölçümler örneklerin PoGo (Dentsply, Konstanz, Almanya) sistemi ile cilalanmasının arkasından yapılmıştır. Son ölçümler ise iki farklı diş macunun disklere uygulanmasının arkasından yapılmış ve her bir değer ayrı ayrı kaydedilmiştir.

Örneklerin yüzey pürüzlülüğü ölçümleri için Profilometre cihazı (Surftest SJ-310 Mitutoyo, ABD) kullanıldı. Cihaz $100 \mu \mathrm{m}$ ölçüm menziline sahip NHT-6 tarayıcı iğneye sahiptir. Bu iğnede EN ISO 3274 standardına uygun $2 \mu \mathrm{m}$ ve $60^{\circ}$ transvers açıya sahip elmas uç bulunmaktadır. Cihaz kalibre edildikten sonra elmas ucun "cut off" degeri 0.25 m olarak ayarlanmıştır ve ölçüm sırasında 0.7 mN' luk ölçme kuvveti uygulamıştır. Her bir grubun ölçümünden önce cihaz kalibre edilmiştir. Örneklerin merkezinde olacak şekilde her bir örnekten 5 ölçüm yapılıp, elde edilen verilerin $(\mathrm{Ra}, \mu \mathrm{m})$ ortalamaları alınarak ortalama yüzey pürüzlülük değerleri hesaplanmıştır.

İstatistiksel değerlendirme, IBM SPSS 20.0 (SPSS Inc., Chicago, IL, Amerika)programı ile yapıldı. Normal dağılıma uygunluk testi Kolmogorov-Smirnov Testi ile değerlendirildi. Normal dağılım gösteren nümerik değişkenler Ortalama +/- standart sapma olarak

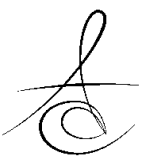


verildi. Gruplar arasındaki farklılık normal dağııma sahip olan nümerik değişkenler için Repeated Tek Yönlü Varyans analizi ile, ikili çoklu karşılaştırmalar ise LSD Post Hoc Test ile değerlendirildi. Bağımlı grup karşılaştırmalarında normal dağıım gösteren değişkenler için paired $\mathrm{t}$ testi kullanıldı. $\mathrm{p}<0.05$ istatistiksel olarak önemlilik için yeterli kabul edildi.

\section{BULGULAR}

Çalışmada elde edilen başlangıç, polisaj sonrası ve diş fırçalama sonrası pürüzlülük değerleri $(R a, \mu \mathrm{m})$, ortalama ve standart sapmaları Tablo 3'de verilmiştir. Bu çalışmanın bulgularına göre bütün materyallerin polisaj işlemi yapılmadan önce ki pürüzlülük değerleri polisaj işlemi yapılmasından sonraki değerlerinden anlamlı olarak düşük bulunmuştur $(p<0.05)$. Polisaj işleminin arkasından yapılan ölçümlerde, Dyract XP $(0,453 \pm 0,11)$; Majesty Posterior $(0,440 \pm 0,20)$; Epricord $(0,415 \pm 0,13)$ ve Aelite $(0,347 \pm 0,21)$ istatistiksel olarak benzer pürüzlülük değerleri sergilemiştir( $p>0.05)$. ken, Aelite, Majesty Posterior ve Dyract XP'nin pürüzlülük değerleri hafif düzeyde azalmış, ancak bu değişim de istatistiksel olarak bir anlamlı bir farkllığa sebep olmamışır ( $p>0.05)$.

\section{TARTIŞMA}

Restoratif materyallerin yüzey özelliklerinin geliştirilmesi restorasyonun uzun ömürlülüğü için gerekli bir parametredir. Restoratif materyallerin mekanik özellikleri materyallerin klinik başarısı üzerinde etkili olurken, aynı şekilde estetik özellikleri de bu materyallerin başarısı üzerinde etkilidir. Restoratif materyallerin önemli bir fiziksel özelliği olan yüzey pürüzlülüğü materyallerin direk olarak parlaklık, renk, sertlik gibi yüzey özelliklerini etkiler. ${ }^{24,25}$ Dolayısıyla bu çalışmada, günlük kullanılan diş macunlarının farklı kullanım alanına sahip restoratif materyallerin yüzey özellikleri üzerindeki etkisi pürüzlülük test metodu ile ölçülmüştür. Bu çalışmanın bulgularına göre oluşturulan kör hipotez "farklı diş macunları, farklı restoratif materyaller üzerinde farklı yüzey pürüzlülük sonuçları sergilemezler" kabul edilmiştir. Bu çalışmada kullanılan

Tablo 3. Çalışmada elde edilen yüzey pürüzlülük değerleri (Ra, $\mu \mathrm{m})$, ortalama ve standart sapmaları.

\begin{tabular}{|c|c|c|c|c|c|}
\hline & $\begin{array}{l}\text { Aelite All Purpose } \\
\text { Body } \\
(\mathrm{Ra}, \mu \mathrm{m})\end{array}$ & $\begin{array}{l}\text { Clearfil Majesty } \\
\text { Posterior } \\
(\mathrm{Ra}, \mu \mathrm{m})\end{array}$ & $\begin{array}{l}\text { Epricord } \\
(\mathbf{R a}, \mu \mathbf{m})\end{array}$ & $\begin{array}{l}\text { Dyract XP } \\
(\mathrm{Ra}, \mu \mathrm{m})\end{array}$ & $\mathbf{p}$ \\
\hline Kontrol grubu & $0.115 \pm 0.10 \mathrm{Aa}$ & $0.132 \pm 0.06 \mathrm{Aab}$ & $0.113 \pm 0.03 \mathrm{Aa}$ & $0.231 \pm 0.11 \mathrm{Ab}$ & 0.031 \\
\hline PoGo polisaj & $0.347 \pm 0.21 \mathrm{Ba}$ & $0.440 \pm 0.20 \mathrm{BCa}$ & $0.415 \pm 0.13 \mathrm{Ba}$ & $0.453 \pm 0.11 \mathrm{Ba}$ & $p>0.05$ \\
\hline Colgate & $0.384 \pm 0.27 \mathrm{Ba}$ & $0.572 \pm 0.14 \mathrm{Ba}$ & $0.398 \pm 0.17 \mathrm{Ba}$ & $0.362 \pm 0.12 \mathrm{Ba}$ & $p>0.05$ \\
\hline Sensodyne & $0.336 \pm 0.15 \mathrm{Ba}$ & $0.328 \pm 0.15 \mathrm{Ca}$ & $0.422 \pm 0.19 \mathrm{Ba}$ & $0.376 \pm 0.11 \mathrm{Ba}$ & $p>0.05$ \\
\hline $\mathbf{p}$ & 0.026 & $<0.001$ & $<0.001$ & 0.002 & \\
\hline
\end{tabular}

Colgate ve Sensodyne diş macunu uygulamalarının arkasından yapılan ölçümlerde, çalışmada kullanılan dört restoratif materyalin de birbirleri ile istatistiksel olarak benzer sonuçlar sergilediği tespit edilmiştir ( $p>0.05)$.

Colgate diş macunu uygulamasının arkasından, Aelite ve Majesty Posterior'un pürüzlülük değerleri hafif düzeyde artarken, Epricord ve Dyract XP'nin pürüzlülük değerleri hafif düzeyde azalmıştır, ancak bu değişim istatistiksel olarak bir anlamlı bir farklılığa sebep olmamıştır ( $p>0.05)$. Sensodyne ile yalnızca Epricord'un pürüzlülük değerleri hafif düzeyde artar- bütün restoratif materyallerin yüzey pürüzlülük değerleri başlangıç ve iki farklı diş macunu ile fırçalama işlemi sonrasında istatistiksel olarak benzer bulunmuştur. Ancak kompozit rezinlerin yüzeyine Colgate diş macunu uygulaması sonucu Aelite ve Majesty Posterior'un yüzey pürüzlülülük değerleri hafif düzeyde artarken, aynı materyallere Sensodyne uygulanması sonucu pürüzlülük değerleri hafif düzeyde azalmıştır.

Kompozit rezin materyallerin diş macunu ile fırçalanması sonucunda materyallerin yüzey özellikleri değişebilir ya da bozulabilir. Bu bozulmada diş macunun içeriğindeki aşındırıcı partikül boyutları, diş fırça-

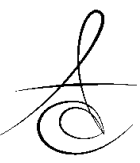


sının tipi ve kullanılan kompozit materyal etkilidir. ${ }^{26}$ Yapılan çalışmalarda kompozit rezin materyallerinin polimerize edildikten sonraki en düşük pürüzlülük değerinin şeffaf strip bant kullanılarak elde edildiği bildirilmiştir. ${ }^{20,25,27}$ Ancak şeffaf bant kullanılarak bitirilen restorasyonların en üst tabakasında oksijen inhibisyon tabakası bulunması sebebiyle, oluşan bu tabakanın materyalin yüzey sertliğini azalttığı, ${ }^{28}$ mekanik özelliklerini bozduğu ve restorasyonlarda renkleşmeye sebep olduğu; ${ }^{29}$ dolayısıyla ortamdan uzaklaştırılması gerektiği bildirilmiştir. Bu tabakayı kaldırmak ve ortamdan uzaklaştırmak için bitirme ve cila işlemleri gereklidir. Dolayısıyla bu çalışmada hazırınan disklere fırçalama işlemi uygulanmadan önce cila işlemi yapılmıştır.

Restorasyonların tamamlanması sürecinde yaptığımız bitirme ve cila işlemleri hem restoratif materyallerin estetik özelliklerini geliştirme hem de plak birikimini önleme açısından önemli bir aşamadır. ${ }^{30-32}$ Restorasyonların yüzey pürüzlülük değerleri, kompozit rezinlerin içeriği ya da polisaj işleminde kullanılan sistemlere bağlı olarak değişebilmektedir. ${ }^{19,30,31}$ Günümüzde cila sistemleri tek aşamalı ve çok aşamalı olarak farklı kategorilerde toplanabilir. Tek aşamalı cila sistemleri kliniklerde zaman ve maliyetin azaltması açısından tercih edilmektedir. Bu nedenle bu çalışmada tek aşamalı PoGo kiti kullanılmıştır. Ereifej ve arkadaşları $^{25}$ PoGo'nun çok aşamalı sistemlere göre daha pürüzsüz restorasyon yüzeyleri oluşturduğunu bildirmişlerdir.

Diş macunları, günlük ağız bakımının temel ürünü olarak kullanılmakta ve çalışmalarda sıklıkla yer almaktadır. ${ }^{26,32-35}$ Diş yüzeyi temizliğini gerçekleştirmek amacıyla macunların içeriğinde yer alan aşındırıcı partiküller; hem restoratif materyallerin hem de diş sert dokularının aşınmasında etkili olabilir. Yapılan çalışmalar diş macunları ile restoratif materyalleri fırçalama işleminin, materyallerin yüzey pürüzlülük değerleri üzerinde etkili olduğunu bildirmiştir. ${ }^{21,33,36,37}$

Kamonkhantikul ve arkadaşları ${ }^{32}$ yaptıkları çalışmada kullanılan bütün kompozitlerin (Durafill VS, Filtek Z250, Filtek Z350 XT, Kalore, Venus Diamond, Venus Pearl) fırçalama sonrasında yüzey pürüzlülük değerlerinin arttığını bildirmişlerdir. Heintze ve arkadaşları ${ }^{26}$ diş fırçalama sonrası oluşan pürüzlülüğün hibrit kompozitlerde nano kompozitlere göre daha yüksek olduğunu bildirmiştir. Moraes ve arkadaşları ${ }^{38}$ da diş fırçalama sonucu kompozitlerde oluşan aşınmaları inceledikleri çalışmalarında mikrohibrit ve tepilebilir (packab- le) kompozitlerin, nanohibrit ve mikrofil kompozitlere göre daha fazla aşınma oranı ve pürüzlülük değerleri sergilediklerini bildirmişlerdir. Araştırmacılar yüzey pürüzlülük değerlerindeki değişimin inorganik doldurucu miktarına bağlı olduğunu bildirmişler, doldurucu partikül boyutu büyük olan materyallerin fırçalama sonrasında daha fazla pürüzlülük değerleri sergilediği sonucuna varmışlardır. Bizim çalışmamızda bu araştırmacılardan farklı olarak kompozit tipi fark etmeksizin bütün kompozitlerin başlangıç değerleri ile fırçalama sonrası değerlerinin benzer olduğu sonucuna varılmıştır. Çalışmamızda diğer çalışmalardan farklı olarak materyallerin nispeten kısa süreli olarak fırçalanması başlangıç ve fırçalama sonrası değerlerin benzer çıkması üzerinde etkili olmuş olabilir. Ancak çalışmamı ile benzer şekilde Atalı ve arkadaşları ${ }^{39}$ da mikrohibrit kompozitler ile siloranın fırçalama öncesi ve sonrası pürüzlülük değerlerinin benzer olduğunu ifade etmişlerdir.

$\mathrm{Bu}$ çalışmanın bulgularına göre hibrit kompozit olan Majesty Posterior'un Colgate ile firçalama sonrasında pürüzlülük değerleri artmış ve çalışmadaki en yüksek değerlere ulaşmıştır. Ancak aynı materyalin Sensodyne ile fırçalama sonrası pürüzlülük değerleri azalmıştır. Majesty Posterior'un farklı macunlara ile farklı sonuçlar sergilemesinde, macunların içeriğinde yer alan aşındırıcı partikül boyut, tip ve miktarlarının farklı oranlarda bulunması sebep olabilir. Costa ve arkadaşları $^{20}$ aşındırıcı oranları farklı üç diş macununun, dört farklı kompozit materyalinin yüzey pürüzlülük değerleri üzerindeki etkisini inceledikleri çalışmada, bir kompozit materyali hariç (Durafill VS) aşındırıcılık oranı yüksek olan diş macunun, aşındırıcılık oranı düşük olan diş macununa göre kompozitler üzerinde daha fazla etki oluşturduğunu belirlemişlerdir. Ayrıca araştırmacılar farklı materyaller üzerinde farklı sonuçlar bulunmasında, kompozit içeriğinde yer alan partikül büyüklüğünün etkisinin bulunduğunu ifade etmişlerdir. $^{20}$ Büyük partiküllü kompozitlerin, küçük partiküllü kompozitlere göre daha fazla pürüzlülük değeri sergilemesinde, aşındırıcıların kompozit organik matriksini ortamdan uzaklaştırabilmesi, ancak büyük doldurucular üzerinde etkili olamaması ve bunun sonucu büyük doldurucuların yüzeyde kalarak pürüzlülük değerlerinin artmasına sebep olmuş olması etkili olabilir. Oliveira ve arkadaşları $^{40}$ küçük partikül içerikli nano kompozitlerin büyük partiküllere sahip makrohibrit kompozitlere göre aşınmaya karşı daha dirençli olduklarını ifade etmişlerdir. Bizim çalışmamızda en düşük pürüzlülük değeri

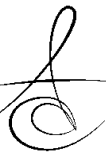


sergilemesi beklenen nanohibrit kompozit Majesty Posterior diğer çalışmalardan farklı olarak yüksek pürüzlülük değerleri sergilemiştir. En büyük partikül büyüklüğüne sahip Aelite ise Majesty Posterior'dan daha düşük pürüzlülük değerleri sergilemiştir. Dolayısıyla bu çalışmanın sınırları içerisinde pürüzlülük değerleri üzerinde partikül büyüklüğünden başka etkenlerinde rolünün olduğu düşünülebilir.

Bu çalışmada, Dyract XP çalışmada kullanılan materyaller içinde, başlangıç zaman diliminde, en yüksek pürüzlülük değerini sergilemiştir. Kompomerler floro alümino silikat cam ve asidik polimer içeren materyaller olup, aşınma dirençleri kompozitler kadar yüksek değildir. Dyract XP'nin bu çalışmada kullanılan diğer materyallerden yüksek pürüzlülük değerleri sergilemesinde aşınmaya karşı sergilemiş olduğu direncin düşük olması gösterilebilir. Diğer yandan, her iki diş macunu ile fırçalama sonrasında Dyract XP'nin pürüzlülük değerlerinde hafif düzeyde bir azalma görülmüştür. Bu azalmaya sebep olarak düşük boyutlu aşındırıcı partikül içeren diş macunlarının, sertliği kompozitlere göre nispeten düşük olan kompomerin yüzeyinde bulunan ve pürüzlülük değerlerinin artmasına sebep olan büyük organik ve inorganik parçacıklarının fırçalamanın mekanik etkisi ile yüzeyden uzaklaşması gösterilebilir. Bu çalışmada kullanılan materyaller içerisinde en düşük oranda inorganik içeriğe sahip materyal Dyract XP'dir. Dyract XP'nin inorganik içeriği diğer materyallerin inorganik içeriğinin hemen hemen yarısı kadardır. Ayrıca Dyract XP'nin partikül büyüklüğünün $0.8 \mu \mathrm{m}$ olduğunu bunun ise kompozitlerin içeriğinde yer alan nano parçacıkları saymazsak, diğer kompozitlerin mikro doldurucu büyüklüğünden (ort; $3,5 \mu \mathrm{m}$ veya $1,5 \mu \mathrm{m}$ ) küçük olduğunu görüyoruz. Dolayısıyla bu çalışmanın bulgularının sınırları içerisinde, kompomerin yüzeyinden daha küçük parçacık kopması sonucu yüzey pürüzlülük değerlerinin azalmış olduğu düşünülebilir

Souza-Rodrigues ve arkadaşları ${ }^{34}$ yaptıkları çaIsşmada, macunların (Oral B 123, Oral B Pro-Health, Freshup, Sorriso Super Refreshing, Colgate Triple Action, Colgate Total 12, Sensodyn Original) içerdikleri aşındırıcıların aktivite düzeylerine göre, materyaller üzerinde farklı sonuçlar oluşturduğunu ifade etmişlerdir. Araştırmacılar Oral B Pro-Health'in Sensodyne'e göre daha fazla abraziv etki gösterdiğini bildirmiş, buna sebep olarak Sensondyne'in abraziv olarak sadece amorphous silika içermesi, Oral B Pro-Healt'in ise hem silika hem de hidrate olmuş silika partikül içermesi olduğunu bildirmişlerdir. Araştırmacılar diğer beş macunun ise Oral B Pro-Health ve Sensodyne'in yarattığı pürüzlülük değerleri arasında değerler sergilediğini ifade etmişlerdir.

West ve arkadaşları ${ }^{41}$ triklosan içeren Colgate Strong Teeth with Cavity Protection'ı stabilize kalay içeren sodyum florid diş macunu Oral-B Pro-Health ile karşılaştırdıkları çalışmada; Colgate'in diş minesi yüzeyinin kaybına karşı koruyucu etkisinin istatistiksel olarak daha az olduğunu bildirmişlerdir. Diğer yandan, Monteiro ve arkadaşları ${ }^{35}$ Oral B Pro-Health Whitening, Colgate Sensitive Pro-Relief ve Colgate Total Clean Mint diş macunları ile yaptıkları çalışmada, en düşük yüzey pürüzlülük değerlerinin Colgate Total Clean Mint ile elde edildiğini bildirmişler ve buna sebep olarak yine macunların içerdikleri abrazivlerin farklı olması olduğunu ifade etmişlerdir. Bizim çalışmamızda Colgate; Aelite ve Majesty Posterior'un pürüzlülük değerlerini arttırmış olup, Epricord ve Dyract XP 'in pürüzlülük değerlerini azaltmıştır. Macunların içeriğindeki aşındırıcı partiküllerin tipi, büyüklüğü ve miktarının farklı olması Colgate ve Sensodyne uygulamaları sonrası farklı sonuçlar elde edilmesi üzerinde etkili olmuş olabilir.

Sonuç olarak, Sensodyne; Aelite, Majesty Posterior ve Dyract XP'nin pürüzsüzlüğünü geliştirirken, Colgate Epricord ve Dyract XP'nin pürüzsüzlüğünü geliştirmiştir. Ancak bu değişim hafif düzeyde olup istatistiksel olarak anlamlılık sergilememiştir.

\section{KAYNAKLAR}

1- Ferracane JL. Resin composite-State of the art dental materials. Dent Mater 2011;27:29-38.

2- Kwon Y, Ferracane J, Lee IB. Effect of layering methods composite type, and flowable liner on the polymerization shrinkage stress of light cured composites. Dent Mater 2012;28:801-9.

3- Manhart J, Kunzelmann $\mathrm{KH}$, Chen HY, Hickel R. Mechanical properties of new composite restorative materials. J Biomed Mater Res 2000;53:353-61.

4- Frankenberger R, García-Godoy F, Lohbauer U, Petschelt A, Krämer N. Evaluation of resin composite materials. Part I: in vitro investigations. Am J Dent 2005;18:23-7.

5- Manhart J, Kunzelmann KH, Chen HY, Hickel R. Mechanical properties and wear behavior of light- 
cured packable composite resins. Dent Mater 2000;16:33-40.

6- Peutzfeldt A. Resin composites in dentistry: the monomer systems. Eur J Oral Sci 1997;105:97116.

7- Senawongse $P$, Pongprueksa $P$. Surface roughness of nanofill and nanohybrid resin composites after polishing and brushing. J Esthet Restor Dent 2007; 19:265-73.

8- Janus J, Fauxpoint G, Arntz Y, Pelletier H, Etienne $O$. Surface roughness and morphology of three nano composites after two different polishing treatments by a multi technique approach. Dent Mater 2010;26:416-25.

9- Moszner N, Klapdohr S. Nanotechnology for dental composites. Int J Nanotechnol 2004;1:130-56.

10- Weitman RT, Eames WB. Plaque accumulation on composite surfaces after various finishing procedures. J Am Dent Assoc1975;91:101-6.

11-Chung KH. Effects of finishing and polishing procedures on the surface texture of resin composites. Dent Mater 1994;10:325-30.

12- Manhart J, Neuerer $P$, ScheibenbogenFuchsbrunner A, Hickel R. Threeyear clinical evaluation of direct and indirect comp osite restorations in posterior teeth. J Prosthet Dent 2000;84:289-96.

13- Hirata $\quad M$, Koizumi $\quad H$, Tanoue $\quad N$, Ogino T, Murakami M, Matsumura $\mathrm{H}$. Influence of laboratory light sources on the wear characteristics of indirect composites. Dent Mater ] 2011;30:127-35.

14- Stawarczyk B, Egli R, Roos M, Ozcan M, Hämmerle $\mathrm{CH}$. The impact of in vitro aging on the mechanica and optical properties of indirect veneering composite resins. J Prosthet Dent 2011;106:38698.

15- Cesar PF, Miranda WG Jr, Braga RR. Influence of shade and storage time on the flexural strength, flexural modulus, and hardness of composites used for indirect restorations. J Prosthet Dent 2001;86:289-96.

16- Pizzo G, La Cara M, Licata ME, Pizzo I, D'angelo M. The effects of an essential oil and an amine fluoride / stannous fluoride mouth rinse on supra gingival plaque regrowth. J Periodontol 2008;79:1177-83.

17- By Michael G. Newman, DDS, Henry Takei, DDS,
MS, Perry R. Klokkevold, DDS, MS and Fermin A. Carranza, Dr. ODONT, Carranza's Clinical Periodontology Expert Consult. 11th Edition, St Louis, Missouri:2012. p.455.

18- Roselino L de M, Cruvinel DR, Chinelatti MA, Piresde-Souza $F$ de $C$. Effect of brushing and accelerated ageing on color stability and surface roughness ofcomposites. J Dent 2013;41:54-61.

19- Roeder LB, Tate WH, Powers JM. Effect of finishing and polishing procedures on the surface roughness of packable composites. Oper Dent 2000;25:53443.

20- da Costa J, Adams-Belusko A, Riley K, Ferracane $J \mathrm{~L}$. The effect of various dentifrices on surface roughness and gloss of resin composites. J Dent 2010;38:123-8.

21- Neme AM, Wagner WC, Pink FE, Frazier KB. The effect of prophylactic polishing pastes and toothbrushingon the surface roughness of resin composite materials in vitro. Oper Dent 2003;28:808-15.

22- Heintze SD, Forjanic M, Ohmiti K, Rousson V. Surface deterioration of dental materials after simulated toothbrushing in relation to brushing time and load. Dent Mater 2010;26:306-19.

23-Gömeç Y, Dörter C, Yıldız E, Efes BG. Diş rengindeki restoratif materyallerin diş fırçalama işlemi sonrasında yüzey özellikleri. İstanbul Univ Diş Hek Fak Derg 1999;33:37-44.

24- Cilli R, Mattos MC, Honorio HM, Rios D, Araujo P, Prakki A. The role of surface sealants in the roughness of composites after a simulated toothbrushing test. J Dent 2009;37:970-7.

25- Ereifej NS, Oweis YG, Eliades G. The effect of polishing technique on 3-D surface roughness and gloss of dental restorative resin composites. Oper Dent 2013;38:1-12.

26- Heintze SD, Forjanic M. Surface roughness of different dental materials before and after simulated toothbrushing in vitro. Oper Dent 2005;30:617-26.

27- Rooder LB, Powers JM. Surface roughness of resin composite prepared by single-use and multi-use diamonds. Am J Dent 2004;17:109-12.

28- Anfe T, Caneppele TMF, Agra CM, Vieira GF. Microhardness assessment of different commercial brands of resin composites with different degrees of translucence. Braz Oral Res 2008;22:358-63. 
29- Park SH, Krejci I, Lutz F. Microhardness of resin composites polymerized by plasma arc or conventional visible light curing. Oper Dent 2002;27:30-7.

30- Neme AL, Frazier KB, Roeder LB, Debner TL. Effect of prophylactic polishing protocols on the surface roughness of esthetic restorative materials. Oper Dent 2002;27:50-8.

31- Joniot S, Salomon JP, Dejou J, Grégoire G. Use of two surface analyzers to evaluate the surface roughness of four esthetic restorative materials after polishing. Oper Dent 2006;31:39-46.

32- Kamonkhantikul K, Arksornnukit M, Takahashi $\mathrm{H}$, Kanehira $\mathrm{M}$, Finger WJ. Polishing and toothbrushing alters the surface roughness and gloss of composite resins. Dent Mater ] 2014;33:599-606.

33- Teixeira EC, Thompson JL, Piascik JR, Thompson JY. In vitro toothbrush-dentifrice abrasion of two restorative composites. J Esthet Restor Dent 2005; 17:172-80.

34- de Souza-Rodrigues RD, Ferreira Sda S, D'AlmeidaCouto RS, Lachowski KM, Sobral MÂ, Marques MM. Choice of toothpaste for the elderly: an in vitro study. Braz Oral Res 2015;29.

35- Monteiro B, Spohr AM. Surface roughness of composite resins after simulated toothbrushing with different dentifrices. J Int Oral Health 2015;7:1-5.

36- Amaral CM, Rodrigues JA, Erhardt MC, Araujo MW, Marchi GM, Heymann HO, Pimenta LA. Effect of whitening dentifrices on the superficial roughness of esthetic restorative materials. J Esthet Restor Dent 2006;18:102-8.

37- Chimello DT, Palma-Dibb RG, Corona SA, Lara EH. Assessing wear and surface roughness of different composite resins after toothbrushing. Mater Res 2001;4:285-9.

38- Moraes RR, Ribeiro Ddos S, Klumb MM, Brandt WC, Correr-Sobrinho L, Bueno $M$. In vitro toothbrushing abrasion of dental resin composites: packable, microhybrid, nanohybrid and microfilled materials. Braz Oral Res 2008;22:112-8.

39- Atalı PY, Öksüz M, Topbaş BF. Fırçalamanın ve beyazlatıcı diş macunların kompozitlerin yüzey özelliklerine etkisi. Atatürk Üniv Diş Hek Fak Derg 2014;24:22-32.
40- Oliveira GU, Mondelli RF, Charantola Rodrigues M, Franco EB, Ishikiriama SK, Wang L. Impact of filler size and distribution on roughness and wear of composite resin after simulated toothbrushing. J Appl Oral Sci 2012;20:510-6.

41- West N, Seong J, Macdonald E, He T, Barker M, Hooper S. A randomized clinical study to measure the anti-erosion benefits of a stannouscontaining sodium fluoride dentifrice. J Indian Soc Periodontol 2015;19:182-7.

\section{Yazışma Adresi}

Yrd. Doç. Dr. Neslihan TEKÇE

Kocaeli Üniversitesi Diş Hekimliği Fakültesi

Restoratif Diş Tedavisi Anabilim Dalı

Yuvacık, Başiskele

KOCAELI

Tel: $\quad 02623442111$

Faks: $\quad 02623442202$

e-mail: neslihan_arslann@hotmail.com 